\title{
Induction of G2/M arrest and apoptosis in human gastric epithelial AGS cells by aqueous extract of Agaricus blazei
}

\author{
CHENG-YUN JIN $^{1 *}$, YUNG HYUN CHOI ${ }^{2 *}$, DONG-OH MOON ${ }^{3}$, CHEOL PARK $^{2}$, YEONG-MIN PARK ${ }^{4}$, \\ SANG-CHEOL JEONG ${ }^{3}$, MOON-SOO HEO ${ }^{3}$, TAE-HO LEE ${ }^{1}$, JAE-DONG LEE ${ }^{1}$ and GI-YOUNG KIM ${ }^{3}$ \\ ${ }^{1}$ Department of Microbiology, College of Natural Sciences, Pusan National University, Pusan 614-714; \\ ${ }^{2}$ Department of Biochemistry, Dongeui University College of Oriental Medicine, Pusan 614-052; \\ ${ }^{3}$ Faculty of Applied Marine Science, Cheju National University, Cheju 690-756; ${ }^{4}$ Department of \\ Microbiology and Immunology, Pusan National University College of Medicine, Pusan 602-739, Korea
}

Received May 3, 2006; Accepted August 2, 2006

\begin{abstract}
Agaricus blazei is well known as a traditional medicinal mushroom and it has been shown to exhibit immunostimulatory and anti-cancer activity. However, the cellular and molecular mechanism of cell cycle arrest and apoptosis of cancer cells is poorly understood. In this study, we have investigated whether A. blazei extract (ABE) exerts anti-proliferative and apoptotic effects on human gastric epithelial AGS cells. It was found that ABE could inhibit cell growth in a dose-dependent manner, which was associated with the arrest of G2/M phase and the induction of apoptotic cell death. Flow cytometric analysis showed that ABE could cause an arrest at the G2/M phase of the cell cycle, which is closely correlated to decreased cyclin B1 and cdc2 levels. Furthermore, this compound induced apoptosis through upregulation of Bax and the activation of caspases with downregulation of XIAP and cIAP-1, but not cIAP-2, and a capase-3 inhibitor could block cell death and apoptotic body formation. These data clearly indicate that ABE-induced apoptosis is associated with caspase- 3 activation. In summary, the growth inhibition of ABE is highly related to cell cycle arrest at the G2/ $\mathrm{M}$ phase and the induction of caspase-3-dependent apoptosis in human gastric epithelial AGS cells.
\end{abstract}

\section{Introduction}

The presence of damaged DNA in the cell activates repair mechanisms as well as signal transduction pathways leading

Correspondence to: Dr Gi-Young Kim, Faculty of Applied Marine Science, Cheju National University, Cheju 690-756, Korea

E-mail: immunkim@cheju.ac.kr

Dr Jae-Dong Lee, Department of Microbiology, College of Natural

Sciences, Pusan National University, Pusan 614-714, Korea

E-mail: leejd@pusan.ac.kr

${ }^{*}$ Contributed equally

Key words: Agaricus blazei, G2/M arrest, apoptosis, human gastric AGS cell to cell cycle arrest and programmed cell death. The progression of eukaryotic cells through the cell cycle is orchestrated by sequential activation and inactivation of the cyclin-dependent kinases (cdks) associated with their respective cyclin subunits $(1,2)$. G1 progression and G1/S transition are regulated by cdk4/cdk6 that assembles with D-type cyclins in mid-G1 and cdk2 that combines later with cyclin $\mathrm{E}$. While cdk2 controls the S-phase when associated with cyclin A, G2/M transition is regulated by cdc2 in combination with cyclins A and B (3-6). It has been conclusively thought that cell cycle arrest-inducing compounds are promising candidates for the treatment and prevention of various cancers. Apoptosis has also provided a number of clues with respect to effective anti-cancer therapy, and many chemotherapeutic agents exert their anti-tumor effects by inducing apoptosis in cancer cells (7). In this process, caspases are essential for the execution of cell death by various apoptotic stimuli $(8,9)$, and caspase activation is regulated by various cellular proteins, including the inhibitor of apoptosis protein (IAP) $(10,11)$ and Bcl-2 family proteins $(12,13)$. Executioner caspases cleave poly(ADP-ribose) polymerase (PARP), which is an execution mark protein of apoptosis (14). Then the cells suicide by way of characteristic features such as cell shrinkage, condensation of chromatin and DNA fragmentation (15). Considerable attention has been devoted to the sequence of events referred to as apoptotic cell death.

Many natural dietary extracts in mushrooms have been shown to be potent in the treatment of various cancers $(16,17)$. Mixed extracts from mushroom might contain different chemotherapeutic materials with more than one mechanism of action, thus possessing a combination of different chemotherapeutic effects. It is therefore very important to identify combination effects of mixed extracts from mushrooms. The Basidiomycete fungus Agaricus blazei has been traditionally used as a health food source in Brazil for the prevention of cancer, hyperlipidemia, arteriosclerosis and chronic hepatitis. A. blazei extract $(\mathrm{ABE})$ has been reported to have anti-tumor and antimutagenic effects $(18,19)$. Also, the intratumoral $(20)$ or oral administration (21) of $\mathrm{ABE}$ resulted in the infiltration of natural killer (NK) cells in the tumor sites and increased NK cell activity in animals. Our previous study also demonstrated 
that $\mathrm{ABE}$ induces the phenotypic and functional maturation of murine bone marrow-derived dendritic cells (22). Although numerous studies on the immunostimulatory effects of $\mathrm{ABE}$ have been reported, the cellular and molecular mechanisms underlying ABE-induced cell cycle arrest and apoptosis are not clear.

In this study, to elucidate the further mechanisms of ABE-induced growth arrest and apoptosis, we investigated the effect of $\mathrm{ABE}$ on cell cycle and proliferation in human gastric epithelial AGS cells. We report here that ABE induces a specific $\mathrm{G} 2 / \mathrm{M}$ phase arrest correlated to the down-regulation of cdc2 and cyclin B1. We have further examined the relationship of pro- and anti-apoptotic members of the Bcl-2 and IAP families. Treatment of ABE markedly resulted in the evaluation of a Bax/Bcl-2 ratio and caspase activity, and a down-regulation of IAP family, XIAP-1 and cAIP-1, but not cIAP-2. Finally, the ABE-mediated $\mathrm{G} 2 / \mathrm{M}$ phase arrest closely correlates with the onset of apoptosis.

\section{Materials and methods}

Reagents. Fetal bovine serum (FBS), RPMI-1640, penicillinstreptomycin and trypsine-EDTA were purchased from Gibco BRL (Gaithersburg, MD). 4,6-Diamidino-2-phenyllindile (DAPI), propidium iodide (PI), paraformaldehyde, 3-(4,5Dimethyl-2-thiazolyl)-2,5-diphenyl-2H-tetrazolium bromide (MTT), RNase A and proteinase $\mathrm{K}$ were purchased from Sigma (St. Louis, MO). Caspase activity assay kits were obtained from R\&D systems (Minneapolis, MN). An enhanced chemiluminescence kit was purchased from Amersham (Arlington Heights, IL). Caspase-3 inhibitor 1 (z-DEVDfmk) was obtained from Calbiochem (San Diego, CA). Any other chemicals not specifically cited here were purchased from Sigma. DNA ladder size markers were purchased from Invitrogen (Carlsbad, CA).

Antibodies. Anti-cdc-2, anti-cdk-2, anti-cyclin-A, anti-cyclinB1, anti-Bax, anti-Bcl-2, anti-XIAP, anti-cIAP-1, anti-cIAP-2, anti-capase-3, anti-capase- 8 and anti-capase-9 were purchased from Santa Cruz Biotechnology (Santa Cruz, CA). Anti-PARP was purchased from PharMingen (San Diego, CA) and B-actin from Sigma. Peroxidase-labeled anti-rabbit and anti-mouse polyclonal immunoglobulins were purchased from Amersham.

Preparation of ABE. A. blazei was supplied by Daejeon University Oriental Hospital (Daejeon, Korea), and ABE was prepared as previously described $(22,23)$. Briefly, ABE was isolated from boiling water extract of A. blazei, followed by ethanol precipitation, dialysis, and protein depletion using the Sevag method. It was a type of proteoglycan and the ratio of polysaccharides to peptides is $74 \%: 26 \%$. The ABE was a type of hazel powder dissolved in serum-free RPMI-1640 and then filtered through a $0.22-\mu \mathrm{m}$ filter and stored at $4^{\circ} \mathrm{C}$. Endotoxin was assayed under endotoxin-free experimental conditions using a Limulus Amebocytes Lysate (LAL) pyrogen kit (Biowhittaker Walkersville, MD). The experiments were conducted according to the manufacturer's protocol: $100 \mu 1$ of standards, $\mathrm{ABE}$ or controls were mixed with $100 \mu \mathrm{l}$ of $\mathrm{LAL}$ reagent and incubated for $1 \mathrm{~h}$ at $37^{\circ} \mathrm{C}$. Each tube was then examined for gelation. The quantity of endotoxin in $\mathrm{ABE}$ was $\leq 0.01 \mathrm{ng} / \mathrm{mg}$.
Cell culture and growth study. Human gastric carcinoma AGS cells were purchased from ATCC (Rockville, MD) and cultured in RPMI-1640 medium supplemented with 10\% FBS and $1 \%$ penicillin/streptomycin in a humidified atmosphere with $5 \% \mathrm{CO}_{2}$ incubator at $37^{\circ} \mathrm{C}$. Cells were cultured in the absence and presence of variable concentrations of $\mathrm{ABE}$ for $48 \mathrm{~h}$. The cells were trypsinized, washed with phosphatebuffered saline (PBS) and the viable cells were scored with a hemocytometer through the exclusion of trypan blue. For the morphological study, cells were grown on coverslips and treated with $\mathrm{ABE}$ for $48 \mathrm{~h}$, and then photographed.

Cell viability test. The cells were seeded at a density of $5 \times 10^{4}$ cells $/ \mathrm{ml}$ and then incubated under various conditions as indicated. MTT $(0.5 \mathrm{mg} / \mathrm{ml})$ was subsequently added to each well. After $3 \mathrm{~h}$ of additional incubation, $100 \mu \mathrm{l}$ of a solution containing $10 \%$ SDS ( $\mathrm{pH} 4.8$ ) plus $0.01 \mathrm{~N} \mathrm{HCl}$ was added to dissolve the crystals. The absorption values at $570 \mathrm{~nm}$ were determined with an ELISA plate reader.

Flow cytometric analysis. Cells were trypsinized, washed with PBS, pelleted by low-speed centrifugation, resuspended in citrate buffer and treated with RNase A. Nuclei were stained with PI solution. The DNA content in each cell nucleus was determined by a FACScalibur flow cytometer (Becton-Dickinson, San Jose, CA).

Nuclear staining with DAPI. Cells were washed with cold PBS and fixed with $3.7 \%$ paraformaldehyde in PBS for $10 \mathrm{~min}$ at room temperature. Fixed cells were washed with PBS and stained with DAPI solution for $10 \mathrm{~min}$ at room temperature. The cells were washed two more times with PBS and analyzed using a fluorescence microscope.

DNA fragmentation assay. Cells $\left(1 \times 10^{6}\right)$ were lysed in $100 \mu 1$ of $10 \mathrm{mM}$ Tris-HCl buffer ( $\mathrm{pH}$ 7.4) containing $10 \mathrm{mM}$ EDTA and $0.5 \%$ Triton $\mathrm{X}-100$. After centrifugation for $5 \mathrm{~min}$ at 15,000 rpm, supernatant samples were treated with RNase A and proteinase K. Subsequently, $20 \mu 1$ of $5 \mathrm{M} \mathrm{NaCl}$ and $120 \mu \mathrm{l}$ isopropanol were added to the samples and kept at $-20^{\circ} \mathrm{C}$ for $6 \mathrm{~h}$. Following centrifugation for $15 \mathrm{~min}$ at 15,000 rpm, the pellets were dissolved in $20 \mu \mathrm{l}$ of TE buffer $(10 \mathrm{mM}$ Tris- $\mathrm{HCl}$ and $1 \mathrm{mM}$ EDTA) as loading samples. To assay the DNA fragmentation pattern, samples were loaded onto $1.5 \%$ agarose gel, and electrophoresis was carried out.

Gel electrophoresis and Western blotting. The cells were harvested and lysed, and protein concentrations were quantified using the BioRad protein assay (BioRad Lab., Hercules, CA) and following the procedure described by the manufacturer. Western blot analysis was performed as described. Briefly, an equal amount of protein was subjected to electrophoresis on SDS-polyacrylamide gels and transferred to nitrocellulose membranes by electroblotting. Blots were probed with the desired antibodies for $1 \mathrm{~h}$, incubated with diluted enzymelinked secondary antibody and then visualized by enhanced chemiluminescence (ECL) according to the recommended procedure (Amersham).

Caspase activity assay. Caspase activity was determined by colorimetric assay using a caspase- $-3,-8$, and -9 activation kit 
A)

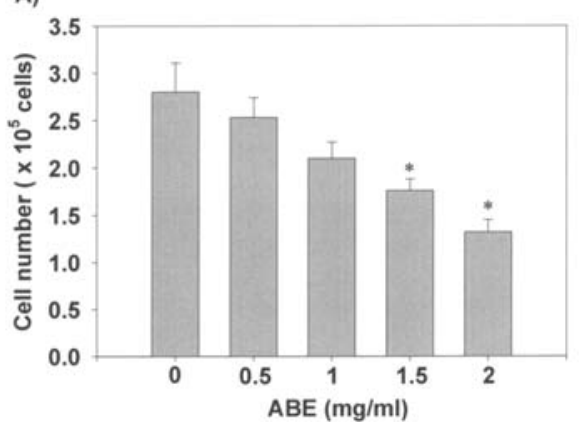

B)

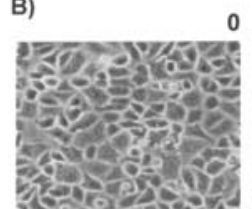

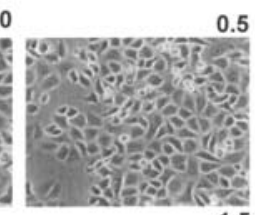
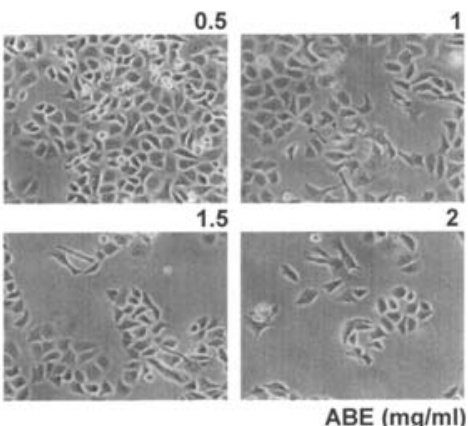

Figure 1. Effect of ABE on the proliferation of human gastric epithelial AGS cells. Cells were seeded at $5 \times 10^{4}$ cells/ml and incubated for 24 h. Cells were cultured in the absence or presence of increasing concentrations of ABE for $48 \mathrm{~h}$. A viable cell number was determined by hemocytometer counts of trypan blue-excluding cells (A). Morphology of cells treated with or without ABE for $48 \mathrm{~h}$ and examined under light microscopy (x400) (B). Each point represents the mean \pm SD of three independent experiments. The significance was determined by Student's t-test ( ${ }^{*} \mathrm{p}<0.05$ vs. untreated control).

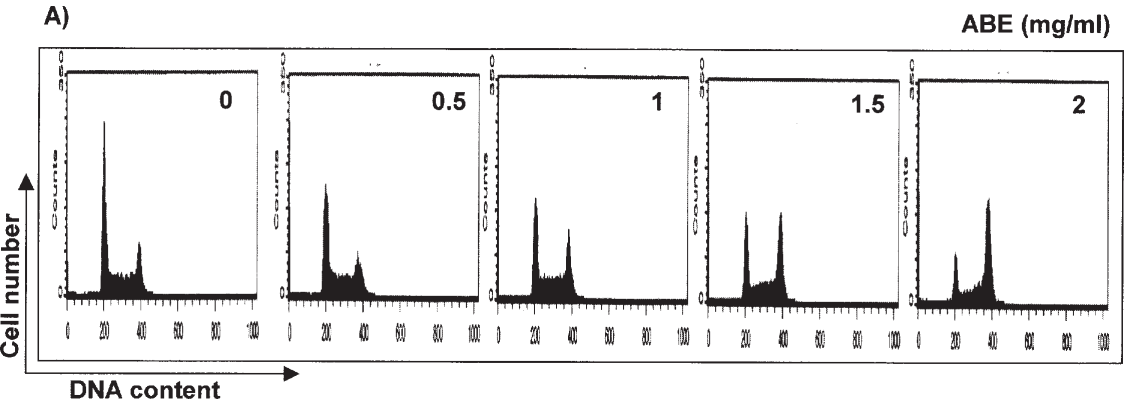

B)

\begin{tabular}{ccccc}
\hline \hline ABE & \multicolumn{5}{c}{$\%$ of cells } \\
\hline$(\mathrm{mg} / \mathrm{ml})$ & sub-G 1 & $\mathrm{G} 1$ & $\mathrm{~S}$ & $\mathrm{G} 2 / \mathrm{M}$ \\
0 & 1.5 & 48.4 & 27.9 & 22.7 \\
0.5 & 4.2 & 47.5 & 26.5 & 22.3 \\
1 & 5.2 & 36.5 & 28.4 & 30.4 \\
1.5 & 5.0 & 27.6 & 26.4 & 41.4 \\
2 & 14.2 & 15.4 & 17.9 & 52.8 \\
\hline \hline
\end{tabular}

Figure 2. Effects of ABE on cell cycle distribution of human gastric epithelial AGS cells. Exponentially growing cells were grown in different concentrations of $\mathrm{ABE}$ for $48 \mathrm{~h}$ and then analyzed by flow cytometry as described (A). The data are from representative experiments repeated three times with similar results (B).

according to the manufacturer's protocol. The kits utilize synthetic tetrapeptides labeled with p-nitroanilide. Briefly, the cells were lysed in the supplied lysis buffer. The supernatants were collected and incubated with the supplied reaction buffer containing dithiothreitol and substrates at $37^{\circ} \mathrm{C}$. The reaction was measured by changes in absorbance at $405 \mathrm{~nm}$ using the VERSAmax tunable microplate reader.

Statistical analysis. All experiments were performed in triplicate. The results of multiple observations were presented as the means $\pm \mathrm{SD}$ of at least three separate experiments. Statistical significance was determined by Student's t-test. A value of $\mathrm{p}<0.05$ was considered to be significant.

\section{Results}

$A B E$ induces growth inhibition in AGS cells. To investigate the effects of inhibition of growth and survival in AGS cells, the cells were exposed to various concentrations $(0-2 \mathrm{mg} / \mathrm{ml})$ of $\mathrm{ABE}$ for $48 \mathrm{~h}$ and their viability was evaluated by trypan blue exclusion and microscope. As shown in Fig. 1A, ABE decreased viable cells in a dose-dependent manner. Compared with control cells $\left[(2.8 \pm 0.3) \times 10^{5}\right.$ cells $], 1.5$ and $2 \mathrm{mg} / \mathrm{ml} \mathrm{ABE}$ significantly inhibited cell viability, $(1.8 \pm 0.1) \times 10^{5}$ cells and $(1.3 \pm 0.1) \times 10^{5}$ cells, respectively. Furthermore, the exposure of $\mathrm{ABE}$ was associated with cellular phenotypic changes such as cell shrinkage and density (Fig. 1B).

ABE modulates G2/M arrest and apoptosis in AGS cells. In order to examine whether growth inhibition is related to cell cycle arrest and apoptosis, we quantified cell cycle distribution and sub-diploid DNA content using flow cytometry. Exponentially growing AGS cells were treated with ABE and subjected to cell cycle analysis after $48 \mathrm{~h}$. As shown in Fig. 2, untreated control cells had $22.7 \%$ of $\mathrm{G} 2 / \mathrm{M}$ phase, whereas the cells treated with 1.5 and $2 \mathrm{mg} / \mathrm{ml} \mathrm{ABE}$ significantly increased 


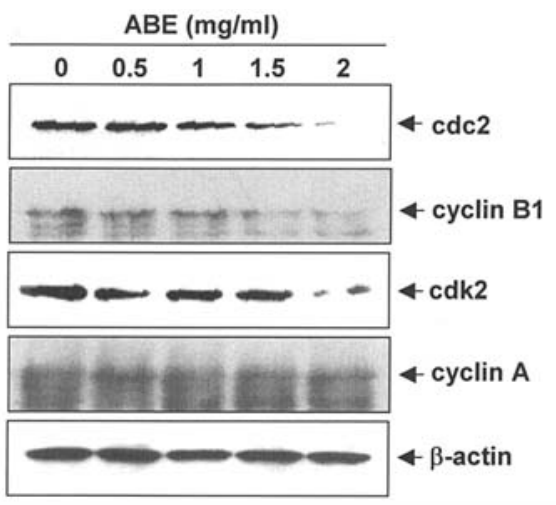

Figure 3. The expression levels of G2/M arrest-related proteins by treatment with ABE in AGS cells. AGS cells were treated with indicated concentrations of ABE. Equal amounts of cell lysates $(30 \mu \mathrm{g})$ were resolved by SDSPAGE, transferred to nitrocellulose, and probed with specific antibodies (anti-cdc2, anti-cdk2, anti-cyclin A and anti-cyclin B1). Representative data are from an experiment repeated three times with similar results.

in the $\mathrm{G} 2 / \mathrm{M}$ phase ( $41.4 \%$ and $52.8 \%$, respectively). ABE increased the population of AGS cells in the G2/M phase in a dose-dependent manner while it decreased the population in the G1 phase. Also, $2 \mathrm{mg} / \mathrm{ml}$ ABE markedly induced the subG1 phase, suggesting apoptosis. The increase in the G2/M phase and apoptosis after ABE exposure was related to a decrease in the $\mathrm{G} 1$ phase, relative to control cells.

$A B E$ inhibits expression of cyclin B1 and $C d c 2$. The cell cycle is tightly regulated through a complex network of cell cycle regulatory molecules such as cdks and cyclins. Since ABE significantly induced G2/M phase arrest in AGS cells (Fig. 2), we examined the expression of cellular proteins of the cell cycle regulating components at the $\mathrm{G} 2 / \mathrm{M}$ boundary, such as cyclin A, cyclin B1, cdk2, and cdc2, whose expression is induced in cells entering $M$ from $G 2$, in response to $A B E$ treatment. As compared to the untreated control, Western blot analysis of the samples obtained after ABE treatment showed no significant change in the protein levels of cyclin A (Fig. 3). On the other hand, ABE treatment resulted in a concentration-dependent decrease in the levels of cdk2, cyclin
$\mathrm{B} 1$, and cdc2, which play important roles in the regulation of the $\mathrm{G} 2 / \mathrm{M}$ transition suggesting that the ABE-induced $\mathrm{G} 2 / \mathrm{M}$ arrest is at least due to its down-regulating effect on the cellular levels of the cyclin B1/cdc2 complex.

$A B E$ induces apoptotic body and DNA fragmentation. To investigate whether ABE causes cell death by apoptosis in AGS cells, DAPI staining and DNA laddering were performed. As shown in Fig. 4, ABE could induce apoptosis in AGS cells in a dose-dependent manner, which was well characterized by apoptotic body formation and nuclear shrinkage (Fig. 4A), and significant DNA fragmentation (Fig. 4B). Induction of apoptosis was almost negligible at a low concentration $(0.5 \mathrm{mg}$ / $\mathrm{ml})$ in control cells.

ABE modulates Bcl-2 and IAP family proteins in AGS cells. The regulation of apoptosis is a complex process and involves a number of Bcl-2 and IAP families. Firstly, to determine the role of the Bcl-2 family in ABE-mediated apoptosis, we investigated the effect of the protein levels of an anti-apoptotic member, Bcl-2, and proapoptotic member, Bax, by Western blot analysis. As shown in Fig. 5A, ABE dose-dependently induced the increase of Bax level, but not the change of Bcl-2 level. A densitometric analysis of the bands revealed that $\mathrm{ABE}$ induced the dose-dependent augmentation in the Bax/Bcl-2 ratio that favors apoptosis (Fig. 5B). Also, the IAP family proteins bind to caspases, which leads to caspase inactivation for an anti-apoptotic effect in eukaryotic cells. We further investigated the involvement of the IAP family, XIAP, cIAP-1, and cIAP-2 in ABE-treated cells. As shown in Fig. 5C, ABEtreated cells dramatically resulted in dose-dependent downregulation of XIAP and cIAP-1, but not cIAP-2. These results suggest that apoptotic actions of ABE are closely related with down-regulation of XIAP and cIAP-1, and up-regulation of Bax.

$A B E$ induces PARP cleavage and caspase activation. It has been shown in recent studies that caspases are very important regulators of apoptosis induced by apoptotic stimuli (8) Therefore, we examined the involvement of various caspases during ABE-induced apoptosis in AGS cells. As shown in
A)
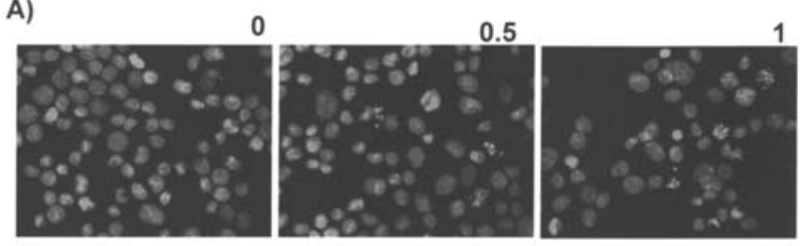

1.5
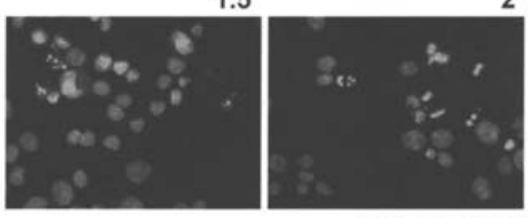

B)

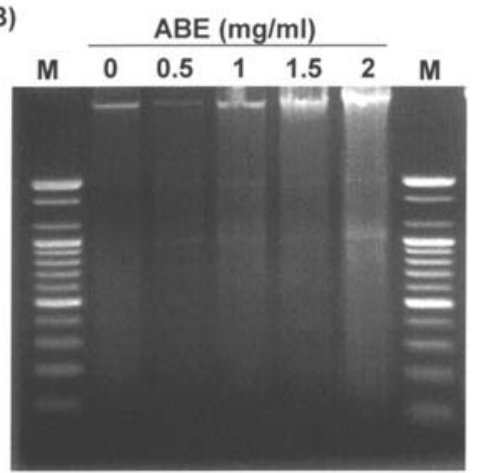

Figure 4. Apoptotic body formation and DNA fragmentation in human gastric epithelial AGS cells treated with increasing concentrations of ABE for $48 \mathrm{~h}$. After 48-h incubation with ABE, the cells were harvested and spun down. After fixing, the cells were stained with DAPI solution, and stained nuclei were then observed under fluorescent microscope using a blue filter [magnification, $\mathrm{x} 400$ (A)]. For the DNA ladder formation the cells were treated with ABE at the specified concentrations for $48 \mathrm{~h}$ and harvested, cellular DNA was isolated, and subjected to agarose gel electrophoresis followed by a visualization of bands (B). Representative data are from an experiment repeated three times with similar results. 
A)

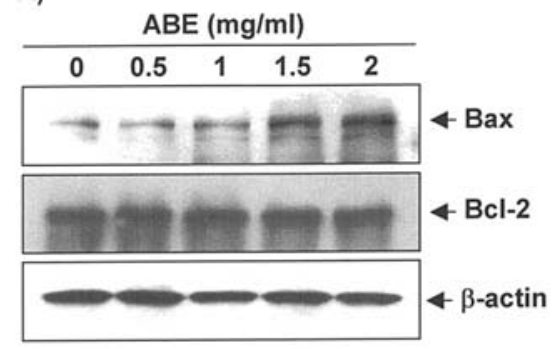

C)

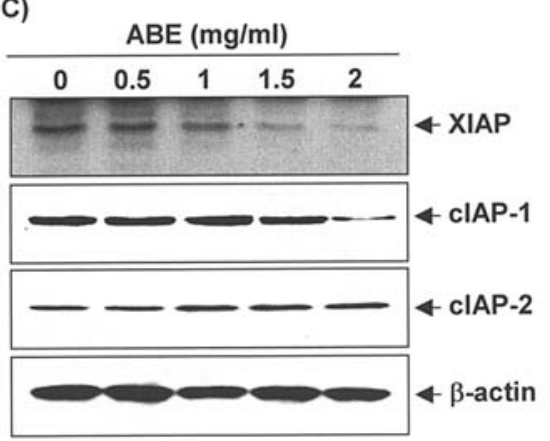

B)

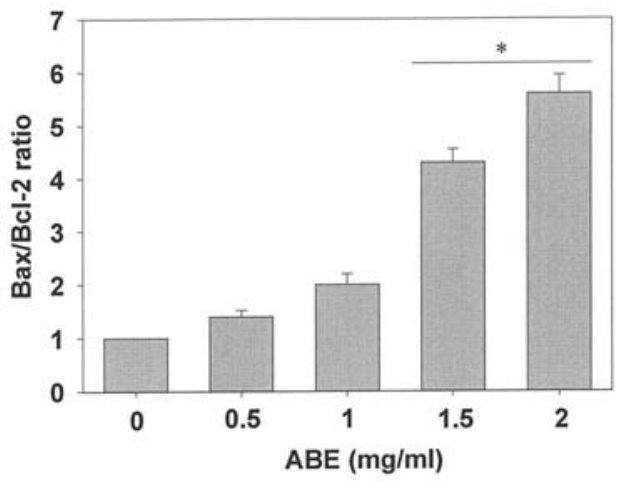

Figure 5. The expression levels of apoptosis-related proteins by treatment with ABE in AGS cells. AGS cells were treated with indicated concentrations of ABE. Equal amounts of cell lysates $(30 \mu \mathrm{g})$ were resolved by SDS-PAGE, transferred to nitrocellulose, and probed with specific antibodies [anti-Bcl-2, antiBax, anti-XIAP, anti-cIAP-1, and anti-cIAP-2] (A and C). A representative study is shown, and two additional experiments yielded similar results. The data obtained from the immunoblot analyses of Bax and Bcl-2 were used to evaluate the effect of $\mathrm{ABE}$ on the Bax/Bcl-2 ratio (B). Data are expressed as mean \pm $\mathrm{SD}$ of three independent experiments. The significance was determined by Student's t-test $\left({ }^{*} \mathrm{p}<0.05\right.$ vs. untreated control).
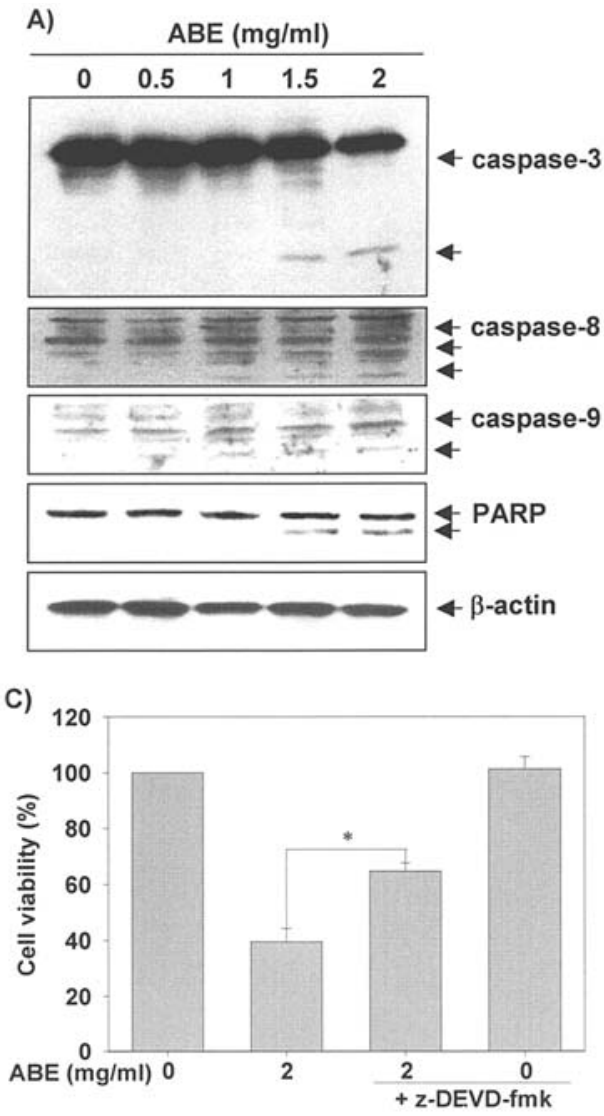

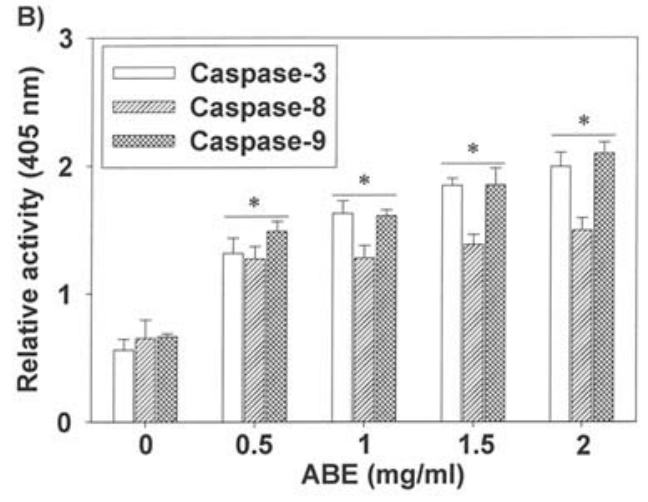

D)

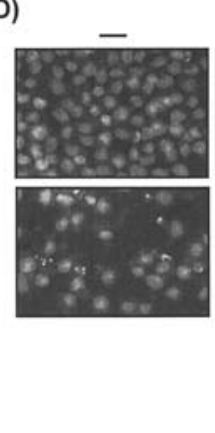

$\mathrm{ABE}(2 \mathrm{mg} / \mathrm{ml})$

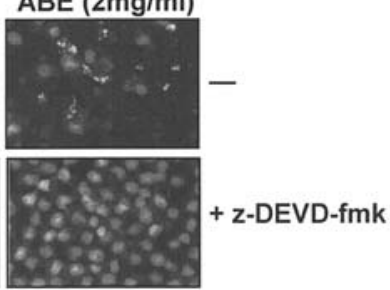

Figure 6. Caspase-3-dependent apoptosis by ABE. The cells were treated with indicated concentrations of ABE. Equal amounts of cell lysates (30 $\mu$ g) were resolved by SDS-PAGE, transferred to nitrocellulose, and probed with specific antibodies (anti-caspase-3, anti-caspase-8, anti-caspase-9, and anti-PARP). Bactin was used as an internal control (A). The results are from one representative experiment of three performed and show similar patterns. (B) Caspase-3, -8 , and -9 activity was determined using a caspase assay kit obtained from R\&D following the manufacturer's protocol. Cell viability (C) and DAPI staining (D) were determined after $48 \mathrm{~h}$ in the presence of the caspase-3 inhibitor z-DEVD-fmk. Data are expressed as mean \pm SD of three independent experiments. The significance was determined by Student's t-test ( ${ }^{*} \mathrm{p}<0.05$ vs. untreated control). 
Fig. 6A, the exposure of $\mathrm{ABE}$ resulted in the reduction of the proform and the induction of the cleaved (active) form of capase-3, -8 , and -9 in a dose-dependent manner. As shown by the Western blot analysis, ABE significantly increased the cleavage of PARP at $1.5-$ and $2-\mathrm{mg} / \mathrm{ml}$ concentrations. We also evaluated the in vitro activity of caspases in AGS cells treated with ABE. As shown in Fig. 6B, ABE exposure significantly increased caspase- $3,-8$, and -9 activity .

To address the significance of caspase- 3 activation in ABE-mediated apoptosis, we used a potent caspase- 3 inhibitor, z-DEVD-fmk. ABE treatment decreased the cell viability (39.6 $\pm 40.8 \%)$ in AGS cells. However, z-DEVD-fmk pre-treated cells significantly increased the cell viability $(64.7 \pm 2.9 \%)$ in ABE-induced apoptosis (Fig. 6C). Furthermore, z-DEVDfmk could decrease apoptotic body formation and nuclear shrinkage in ABE-treated AGS cells (Fig. 6D). These results clearly suggest that caspase-3 closely regulates ABE-mediated apoptosis in AGS cells.

\section{Discussion}

Regulating cell cycle and apoptosis is an important way to maintain cellular homeostasis between cell division and cell death (24). It has been thought that induction of cell cycle arrest and apoptosis is a good strategy for treating cancer. Therefore, many studies were performed for finding cell cycle arrest and apoptosis inducing compounds from mushrooms $(16,17)$. In the present study, we have revealed that ABE inhibited cell proliferation and induced apoptosis in human gastric epithelial AGS cells. The anti-proliferative effect was related to the ability of $A B E$ to provoke growth inhibition at the $G 2 / M$ arrest and apoptosis. ABE induced G2/M arrest through cdc2 and cyclin B1 and increased apoptosis through up-regulation of the Bax protein and the activation of caspase- 3 .

In terms of regulating the cell cycle, cdks play a most critical role. Cdk2 that interacts with cyclins $\mathrm{E}$ and $\mathrm{A}$ has been found to play an important role in the regulation of the $S$ and $\mathrm{G} 2$ phase $(4,25)$. Cdc2 interacts with cyclin $\mathrm{B}$, and activation of the cyclin $\mathrm{B} / \mathrm{cdc} 2$ complex is pivotal for a transition from the $\mathrm{G} 2$ to $\mathrm{M}$ phase $(5,6)$. Based on these reports, we investigated the effects of $\mathrm{ABE}$ on the expression of $\mathrm{G} 2 / \mathrm{M}$ regulatory proteins. The results demonstrated that $\mathrm{ABE}$ decreased the levels of cdk2, cdc2, and cyclin B1, but not cyclin A in AGS cells. These results partially suggested that ABE induces cell cycle by down-regulation of cdk 2 in the early $\mathrm{G} 2$ phases and consequently arrests the cell cycle at G2/M through the modulation of cyclin $\mathrm{B} / \mathrm{cdc} 2$ complex.

The caspase family, aspartate-specific cystein proteases, also plays a critical role in regulating apoptosis and the key components of the biochemical pathways of caspase activation have been elucidated (9). Caspase signaling is initiated and propagated by proteolytic autocatalysis and the cleavage of downstream caspases and substrates such as PARP and lamin A (24). Especially, capase-3 is one of the key executioners of apoptosis, as it is either partially or totally responsible for the proteolytic cleavage of many key proteins, such as PARP (26). PARP is important for cell viability, but the cleavage of PARP facilitates cellular disassembly and serves as a marker of cells undergoing apoptosis (27). In this study, we demonstrated that $\mathrm{ABE}$ induces apoptosis through the activation and cleavage of capase-3, -8 and -9 (Fig. 6). Especially, treatment of ABE in the presence z-DEVD-fmk inhibited cell death and apoptotic body formation. These data suggest that ABE-induced apoptosis was caused by caspase-3-dependent cell death.

This study demonstrated that ABE treatment results in significant cell growth inhibition and the induction of apoptosis in AGS cells. Our next aim was to identify the mechanism of ABE-induced apoptosis in AGS cells. In order to test the mechanism of ABE-induced apoptosis, we also determined the effects of ABE on levels of IAP and Bcl-2 families. Previous studies demonstrated that IAP proteins including XIAP, cIAP-1, and cIAP-2 interact and inhibit selected caspases in vitro and in vivo (28-30). In this experiment, the levels of apoptosis-related IAP families, XIAP and cIAP-1, were down-regulated, but cIAP-2 was not modulated by ABE treatment. It also has been shown that the Bcl-2 family significantly regulates apoptosis either as an activator (Bax) or as an inhibitor (Bcl-2) $(31,32)$. Our data have demonstrated that ABE-induced apoptosis is related to augmented levels of the Bax protein but not down-regulation of Bcl-2. It has been reported that the $\mathrm{Bax} / \mathrm{Bcl}-2$ ratio is recognized as a key factor in regulating the apoptotic process (33). Our analysis of the present data indicates that ABE may increase the Bax/Bcl-2 ratio and lead to apoptosis of AGS cells.

In conclusion, we have demonstrated that $\mathrm{ABE}$ significantly inhibits cell proliferation via the modulation of cell cyclerelated proteins, cdc2 and cyclin $\mathrm{B} 1$, and induces apoptosis via up-regulation of Bax and caspase activity. Therefore, $\mathrm{ABE}$ might be promising molecules in cancer chemoprevention and chemotherapy.

\section{Acknowledgments}

This work was supported by the Korea Research Foundation Grant funded by the Korean Government (MOEHRD) (KRF2005-206-E00007) and partially by the Korea Science and Engineering Foundation through National Research Laboratory Program Grant M10500000008-05J000000810.

\section{References}

1. Sherr CJ: Cancer cell cycles. Science 274: 1672-1677, 1996.

2. Sherr CJ and Roberts JM: Inhibitors of mammalian G1 cyclindependent kinases. Genes Dev 9: 1149-1163, 1995.

3. Girard F, Strausfeld U, Fernandez A and Lamb NJ: Cyclin A is required for the onset of DNA replication in mammalian fibroblasts. Cell 67: 1169-1179, 1991.

4. Guadagno TM, Ohtsubo M, Roberts JM and Assoian RK: A link between cyclin A expression and adhesion-dependent cell cycle progression. Science 262: 1572-1575, 1993.

5. King RW, Jackson PK and Kirschner MW: Mitosis in transition. Cell 79: 563-571, 1994.

6. Krek W and Nigg EA: Differential phosphorylation of vertebrate p34cdc2 kinase at the G1/S and G2/M transitions of the cell cycle: identification of major phosphorylation sites. EMBO J 10: 305-316, 1991.

7. Kamesaki H: Mechanisms involved in chemotherapy-induced apoptosis and their implications in cancer chemotherapy. Int $\mathrm{J}$ Hematol 68: 29-43, 1998

8. Earnshaw WC, Martins LM and Kaufmann SH: Mammalian caspases: structure, activation, substrates, and functions during apoptosis. Annu Rev Biochem 68: 383-424, 1999.

9. Stennicke HR and Salvesen GS: Properties of the caspases. Biochim Biophys Acta 1387: 17-31, 1998.

10. Roy N, Deveraux QL, Takahashi R, Salvesen GS and Reed JC: The c-IAP-1 and c-IAP-2 proteins are direct inhibitors of specific caspases. EMBO J 16: 6914-6925, 1997. 
11. Deveraux QL and Reed JC: IAP family proteins - suppressors of apoptosis. Genes Dev 13: 239-252, 1999.

12. Reed JC, Miyashita T, Takayama S, Wang HG, Sato T, Krajewski S, Aime-Sempe C, Bodrug S, Kitada S and Hanada M: BCL-2 family proteins: regulators of cell death involved in the pathogenesis of cancer and resistance to therapy. J Cell Biochem 60: 23-32, 1996.

13. Rosse T, Olivier R, Monney L, Rager M, Conus S, Fellay I, Jansen B and Borner C: Bcl-2 prolongs cell survival after Baxinduced release of cytochrome c. Nature 391: 496-499, 1998.

14. Lazebnik YA, Kaufmann SH, Desnoyers S, Poirier GG and Earnshaw WC: Cleavage of poly(ADP-ribose) polymerase by a proteinase with properties like ICE. Nature 371: 346-347, 1994.

15. Evans VG: Multiple pathways to apoptosis. Cell Biol Int 17: 461-476, 1993.

16. Hu H, Ahn NS, Yang X, Lee YS and Kang KS: Ganoderma lucidum extract induces cell cycle arrest and apoptosis in MCF-7 human breast cancer cell. Int J Cancer 102: 250-253, 2002.

17. Yang HL, Chen CS, Chang WH, Lu FJ, Lai YC, Chen CC, Hseu TH, Kuo C and Hseu YC: Growth inhibition and induction of apoptosis in MCF-7 breast cancer cells by Antrodia camphorata. Cancer Lett 231: 215-227, 2006.

18. Kawagishi H, Nomura A, Yumen T, Mizuno T, Hagiwara T and Nakamura $\mathrm{T}$ : Isolation and properties of a lectin from the fruiting bodies of Agaricus blazei. Carbohydr Res 183: 150-154, 1988.

19. Takaku T, Kimura Y and Okuda H: Isolation of an antitumor compound from Agaricus blazei Murill and its mechanism of action. J Nutr 131: 1409-1413, 2001.

20. Ahn WS, Kim DJ, Chae GT, Lee JM, Bae SM, Sin JI, Kim YW, Namkoong SE and Lee IP: Natural killer cell activity and quality of life were improved by consumption of a mushroom extract, Agaricus blazei Murill Kyowa, in gynecological cancer patients undergoing chemotherapy. Int J Gynecol Cancer 14: 589-594, 2004

21. Oshiman K, Fujimiya Y, Ebina T, Suzuki I and Noji M: Orally administered beta-1,6-D-polyglucose extracted from Agaricus blazei results in tumor regression in tumor-bearing mice. Planta Med 68, 610-614, 2002.
22. Kim GY, Lee MY, Lee HJ, Moon DO, Lee CM, Jin CY, Choi YH, Jeong YK, Chung KT, Lee JY, Choi IH and Park YM: Effect of water-soluble proteoglycan isolated from Agaricus blazei on the maturation of murine bone marrow-derived dendritic cells. Int Immunopharmacol 5: 1523-1532, 2005

23. Ohno N, Furukawa M, Miura NN, Adachi Y, Motoi M and Yadomae T: Antitumor beta glucan from the cultured fruit body of Agaricus blazei. Biol Pharm Bull 24: 820-828, 2001.

24. Hengartner MO: The biochemistry of apoptosis. Nature 407 770-776, 2000.

25. Ling YH, el-Naggar AK, Priebe $\mathrm{W}$ and Perez-Soler R: Cell cycle-dependent cytotoxicity, G2/M phase arrest, and disruption of p34cdc2/cyclin B1 activity induced by doxorubicin in synchronized P388 cells. Mol Pharmacol 49: 832-841, 1996.

26. Fernandes-Alnemri T, Litwack G and Alnemri ES: CPP32, a novel human apoptotic protein with homology to Caenorhabditis elegans cell death protein Ced-3 and mammalian interleukin-1 beta-converting enzyme. J Biol Chem 269: 30761-30764, 1994.

27. Oliver FJ, de la Rubia G, Rolli V, Ruiz-Ruiz MC, de Murcia G and Murcia JM: Importance of poly(ADP-ribose) polymerase and its cleavage in apoptosis. Lesson from an uncleavable mutant. J Biol Chem 273: 33533-33539, 1998.

28. Hawkins CJ, Uren AG, Hacker G, Medcalf RL and Vaux DL: Inhibition of interleukin 1 beta-converting enzyme-mediated apoptosis of mammalian cells by baculovirus IAP. Proc Natl Acad Sci USA 93: 13786-13790, 1996.

29. Hozak RR, Manji GA and Friesen PD: The BIR motifs mediate dominant interference and oligomerization of inhibitor of apoptosis Op-IAP. Mol Cell Biol 20: 1877-1885, 2000.

30. Luque LE, Grape KP and Junker M: A highly conserved arginine is critical for the functional folding of inhibitor of apoptosis (IAP) BIR domains. Biochemistry 41: 13663-13671, 2002.

31. Adams JM and Cory S: The Bcl-2 protein family: arbiters of cell survival. Science 281: 1322-1326, 1998.

32. Oltvai ZN, Milliman CL and Korsmeyer SJ: Bcl-2 heterodimerizes in vivo with a conserved homolog, Bax, that accelerates programmed cell death. Cell 74: 609-619, 1993.

33. Jacobson MD, Burne JF and Raff MC: Mechanisms of programmed cell death and $\mathrm{Bcl}-2$ protection. Biochem Soc Trans 22: 600-602, 1994. 